\title{
Influence of a carbon-based tribofilm induced by the friction temperature on the tribological properties of impregnated graphite sliding against a cemented carbide
}

\author{
Jun ZHAO ${ }^{1}$, Qingzhan LI $^{1}$, Shuangxi LI $^{1, *}$, Shicong LI ${ }^{1}$, Guangyan CHEN ${ }^{2}$, Xinghua LIU $^{1}$, Yongyong HE $^{2, *}$, \\ Jianbin LUO' \\ ${ }^{1}$ College of Mechanical and Electrical Engineering, Beijing University of Chemical Technology, Beijing 100029, China \\ ${ }^{2}$ State Key Laboratory of Tribology, Tsinghua University, Beijing 100084, China \\ Received: 20 July 2019 / Revised: 06 November 2019 / Accepted: 18 December 2019 \\ (C) The author(s) 2019.
}

\begin{abstract}
Impregnated graphite has attracted considerable attention and has been widely used as an ideal friction material in many fields. However, the influence of the friction temperature on its tribological properties has not been clearly studied; furthermore, the evolution mechanism of transferred tribofilm is unknown. In this study, the tribological properties of impregnated graphite were investigated at different friction temperatures, and the evolution of the carbon-based tribofilm was also determined. The results revealed that the tribological properties significantly improved with an increase in friction temperature. The friction coefficient and wear depth of impregnated graphite reduced by $68 \%$ and $75 \%$, respectively, at a high temperature of $160{ }^{\circ} \mathrm{C}$ compared with those of non-impregnated graphite. The significant properties of the impregnated graphite can be attributed to a transferred carbon-based tribofilm with an ordered structure induced by the friction temperature, which uniformly and stably adsorbs on friction interfaces. This study provides an important basis for designing graphite-based friction materials with improved properties suited for industrial applications.
\end{abstract}

Keywords: impregnated graphite; tribological properties; tribofilm; friction mechanism

\section{Introduction}

Graphite materials have been widely used as ideal friction materials in various equipment such as mechanical seals, bearings of canned pumps, and electrical contact systems, because of their high thermal conductivity, excellent chemical stability, and outstanding tribological properties [1-3]. In general, graphite contains many pores, which are generated during the manufacturing processes; hence, to improve its properties, it is usually impregnated with metals or resins that fill its open pores [4, 5]. Recently, impregnated graphite has attracted considerable attention because it shows better tribological pro- perties than non-impregnated graphite. Hirai et al. [6] and Zhu et al. [7] studied the tribological properties of impregnated materials used in rotary joints under dry friction conditions. They found that the tribological properties of impregnated graphite were superior to those of non-impregnated graphite, and that the former can be used under high load for long-term sliding. Wang et al. [8] discussed the effect of electrical currents on the tribological behavior of metal-impregnated graphite. Qian et al. [9] focused on their corrosionwear resistance under a corrosive environment. Zhang et al. $[1,10]$ reported that resin-impregnated graphite exhibited superior tribological properties under water lubrication than non-impregnated graphite and

* Corresponding authors: Shuangxi LI, E-mail: buctlsx@126.com; Yongyong HE, E-mail: heyy@mail.tsinghua.edu.cn 
that the resin-impregnated graphite could remain in a stable friction regime under high sliding velocities and high pressures.

The friction and wear mechanisms of graphite have been thoroughly investigated in previous studies. Graphite has a lamellar structure with weak interplanar van der Waals forces, which allows it to easily slide between carbon interlayers during friction [11-13]. In addition, water from the environment is able to penetrate the graphite layers, which allows for easier shearing effects, further decreasing friction and wear $[3,14,15]$. Besides, the carbon-based tribofilm from graphite transferred onto the counterpart surfaces can effectively protect friction interfaces [16-18]. The friction mechanism of resin-impregnated graphite is also revealed under certain friction conditions [19]. Pure resins show good tribological properties by forming stable transfer films on counterpart surfaces [20-22], which suggests that a carbon-based tribofilm forms on resin-impregnated graphite [23]. However, studies on the physical and chemical structure evolution of the tribofilm during friction are lacking. In particular, although the tribological properties of impregnated graphite have been widely studied under various friction and environment conditions, the influence of the friction temperature on their tribological properties remains to be clearly elucidated, and the evolution mechanism of the transferred tribofilm is still unknown.

We studied the tribological properties of resinimpregnated graphite at different friction temperatures and revealed the evolution of a carbon-based tribofilm for the first time. In particular, we analyzed the evolution of the friction and wear characteristics with changes in temperature to understand the influence of temperature on the formation of the carbon-based tribofilm. The results provide an important experimental basis for designing high-property graphitebased friction materials in industrial applications.

\section{Experimental}

\subsection{Materials}

The initial non-impregnated graphite exhibited a porous structure with an open porosity of about $15 \mathrm{vol} \%$. After the impregnation process $[1,7,9]$, the pores disappeared, which improved the performance of the graphite. The furan resin-impregnated graphite and non-impregnated graphite were provided by Shanghai Morgan Advanced Materials Co., Ltd. As cemented carbides have been widely used in mechanical seals and bearings, tungsten carbide (WC) balls purchased from Zhejiang Jienaier New Material Co., Ltd. were used as friction counterparts. The main mechanical and physical parameters of these materials are listed in Table 1.

\subsection{Friction tests}

The tribological tests were carried out on a ball-ondisc test rig of a reciprocating friction tester (UMT-3, CETR, USA). The schematic diagram of the test is illustrated in Fig. 1. The friction flat disc and the sliding ball (Ø $4 \mathrm{~mm}$ ) were made of graphite and cemented carbides as shown in Figs. 2(a)-2(d). Before testing, the graphite surfaces were polished by a brass lapping machine. The surface roughness of the impregnated and non-impregnated graphite were $54 \mathrm{~nm}$ and $57 \mathrm{~nm}$, respectively, as shown in Table 1. The chemical formula of furan resin is shown in the inset of Fig. 2(e). Furan has several characteristic adsorption peaks. The $\mathrm{O}-\mathrm{H}$ stretching vibration is clearly observed at about $3,400 \mathrm{~cm}^{-1}$, and the absorption bands at $1,625 \mathrm{~cm}^{-1}$ and $1,080 \mathrm{~cm}^{-1}$ are, respectively, due to the $\mathrm{C}=\mathrm{C}$ and $\mathrm{C}-\mathrm{O}-\mathrm{C}$ stretching vibrations of furan resin $[24,25]$. In addition, there is an obvious XPS spectrum peak at $283.20 \mathrm{eV}$ due to $\mathrm{C}-\mathrm{C} / \mathrm{C}=\mathrm{C}$. The XPS spectrum of the $\mathrm{C} 1 \mathrm{~s}$ also shows the presence of the oxygencontaining functional groups of $\mathrm{C}=\mathrm{O}(287.25 \mathrm{eV})$ and

Table 1 Mechanical and physical parameters of test materials.

\begin{tabular}{ccccccc}
\hline Material & $\begin{array}{c}\text { Roughness, Ra } \\
(\mathrm{nm})\end{array}$ & $\begin{array}{c}\text { Kurtosis, } \\
\mathrm{Rku}\end{array}$ & $\begin{array}{c}\text { Skewness, } \\
\text { Rsk }\end{array}$ & $\begin{array}{c}\text { Shore hardness, } \\
\text { HS }\end{array}$ & $\begin{array}{c}\text { Young's modulus } \\
(\mathrm{GPa})\end{array}$ & $\begin{array}{c}\text { Open porosity } \\
(\mathrm{vol} \%)\end{array}$ \\
\hline Cemented carbide & 12 & 2.58 & -0.45 & 90 & 510 & - \\
Non-impregnated graphite & 57 & 7.62 & 0.33 & 60 & 70 & 18 \\
Impregnated graphite & 54 & 10.61 & 0.82 & 25 & - \\
\hline
\end{tabular}




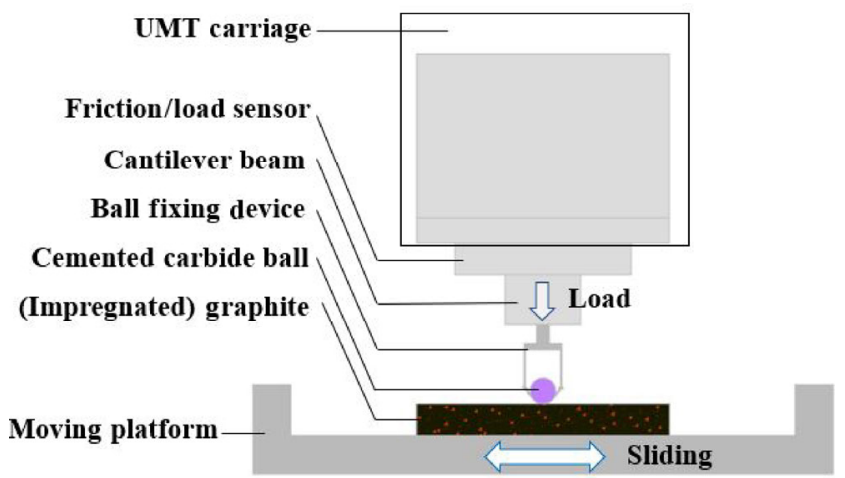

Fig. 1 Schematic illustration of sliding friction test.

C-O $(284.58 \mathrm{eV})$, which are probably due to the resin shown in Fig. 2(b) [26, 27]. The experimental parameters used in this study are given in Table 2.

\subsection{Characterization}

The morphologies of initial surfaces and wear tracks were observed by a white-light interferometer (MICROXAM-3D, USA), and the wear morphologies were also analyzed via an optical microscope (Schneider Electric, Germany), a scanning electron microscope (SEM, FEI Quanta 200 FEG, Netherlands) with a secondary electron condition, and an accelerating voltage of $5 \mathrm{kV}$. The Fourier transform infrared spectroscopy (FTIR) and Raman spectra were measured by a Nicolet Nexus FTIR spectrometer in the region of $500-4,000 \mathrm{~cm}^{-1}$ and a Raman spectrometer (Horba JobinYvon, France) with $532 \mathrm{~nm}$ laser excitation. The carbon-based tribofilm was characterized by an energy

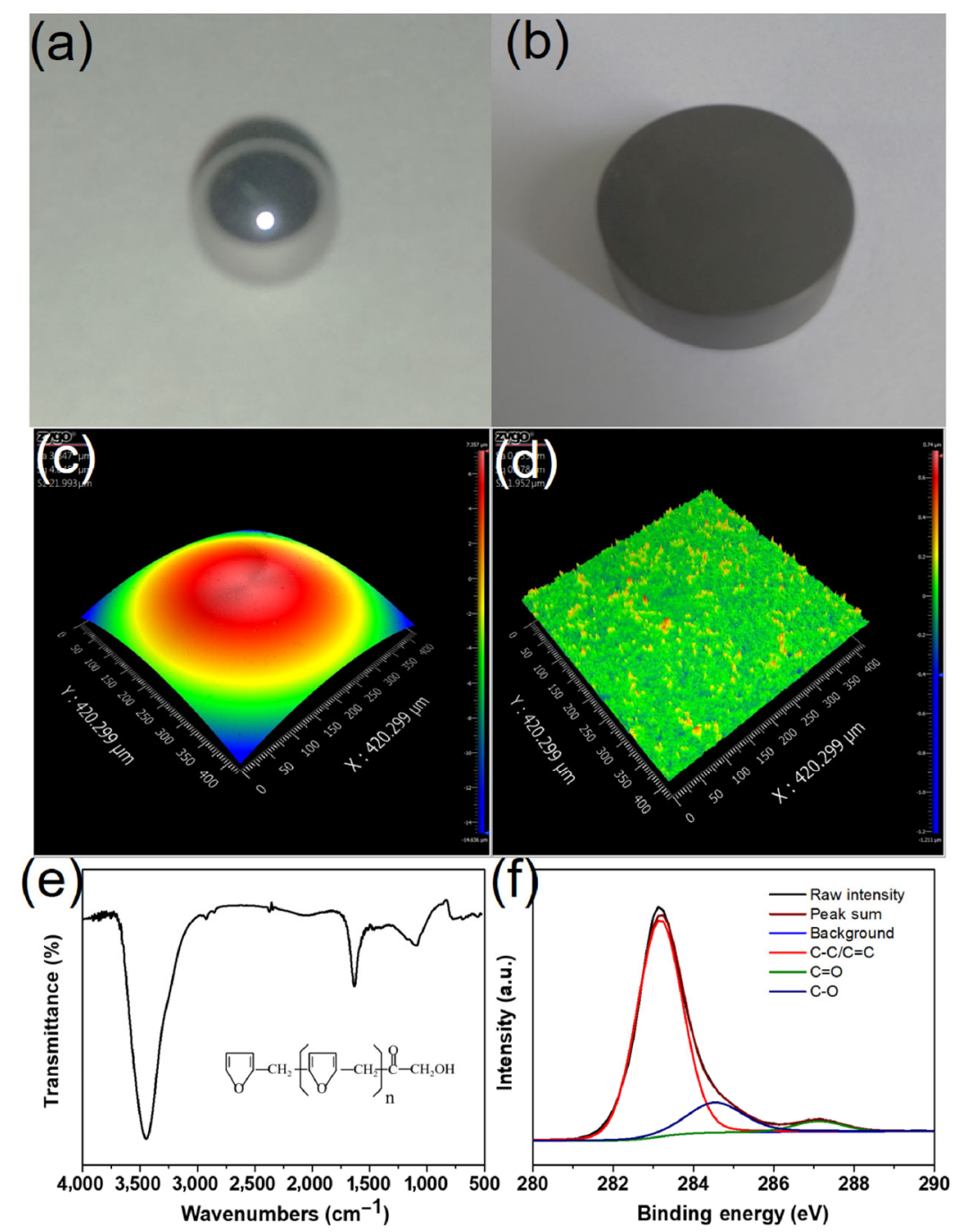

Fig. 2 Optical micrographs of cemented carbide ball (a) and impregnated graphite (b), three-dimensional topographies of the ball (c) and the impregnated graphite (d), FTIR (e), and XPS (f) spectra of impregnated graphite. The inset (e) displays the chemical formula of furan resin. 
Table 2 Experimental conditions and parameters for friction tests.

\begin{tabular}{cc}
\hline Experimental condition & Parameter \\
\hline Temperature & $20-160{ }^{\circ} \mathrm{C}$ \\
Sliding frequency & $5 \mathrm{~Hz}$ \\
Sliding stroke & $3 \mathrm{~mm}$ \\
Friction load & $2-8 \mathrm{~N}$ \\
\hline
\end{tabular}

dispersive $\mathrm{X}$-ray detector (EDX) with an accelerating voltage of $5 \mathrm{kV}$, an X-ray photoelectron spectroscope (XPS, Thermo Fisher Scientific, USA) operating with $\mathrm{Al}-\mathrm{K} \alpha$ radiation, and Raman spectrometer to determine the friction mechanisms.

\section{Results and discussion}

\subsection{Friction properties}

The friction properties of impregnated and nonimpregnated graphite under different friction conditions are shown in Fig. 3. It can be seen that the coefficient of friction (COF) of the impregnated graphite is slightly lower than that of non-impregnated graphite at a low friction temperature $\left(20^{\circ} \mathrm{C}\right)$ (Fig. 3(a)). At a high temperature $\left(160^{\circ} \mathrm{C}\right)$, the starting COF value of the impregnated graphite is as large as that of the non-impregnated graphite. However, the value quickly decreases and reaches a minimum of 0.07 for the impregnated graphite. For comparison, the COF of the non-impregnated graphite fluctuates between various values, and the corresponding average value is as high as 0.22, as shown in Fig. 3(b). Figure 3(c) shows the friction behaviors of the two types of graphite at various friction temperatures. With an increase in temperature, the COF of the impregnated graphite decreases dramatically. In particular, when the temperature is more than $100{ }^{\circ} \mathrm{C}$, the impregnated graphite has outstanding friction properties, and the COF value does not further reduce at a higher temperature $\left(140{ }^{\circ} \mathrm{C}\right)$. On the contrary, the COF of the non-
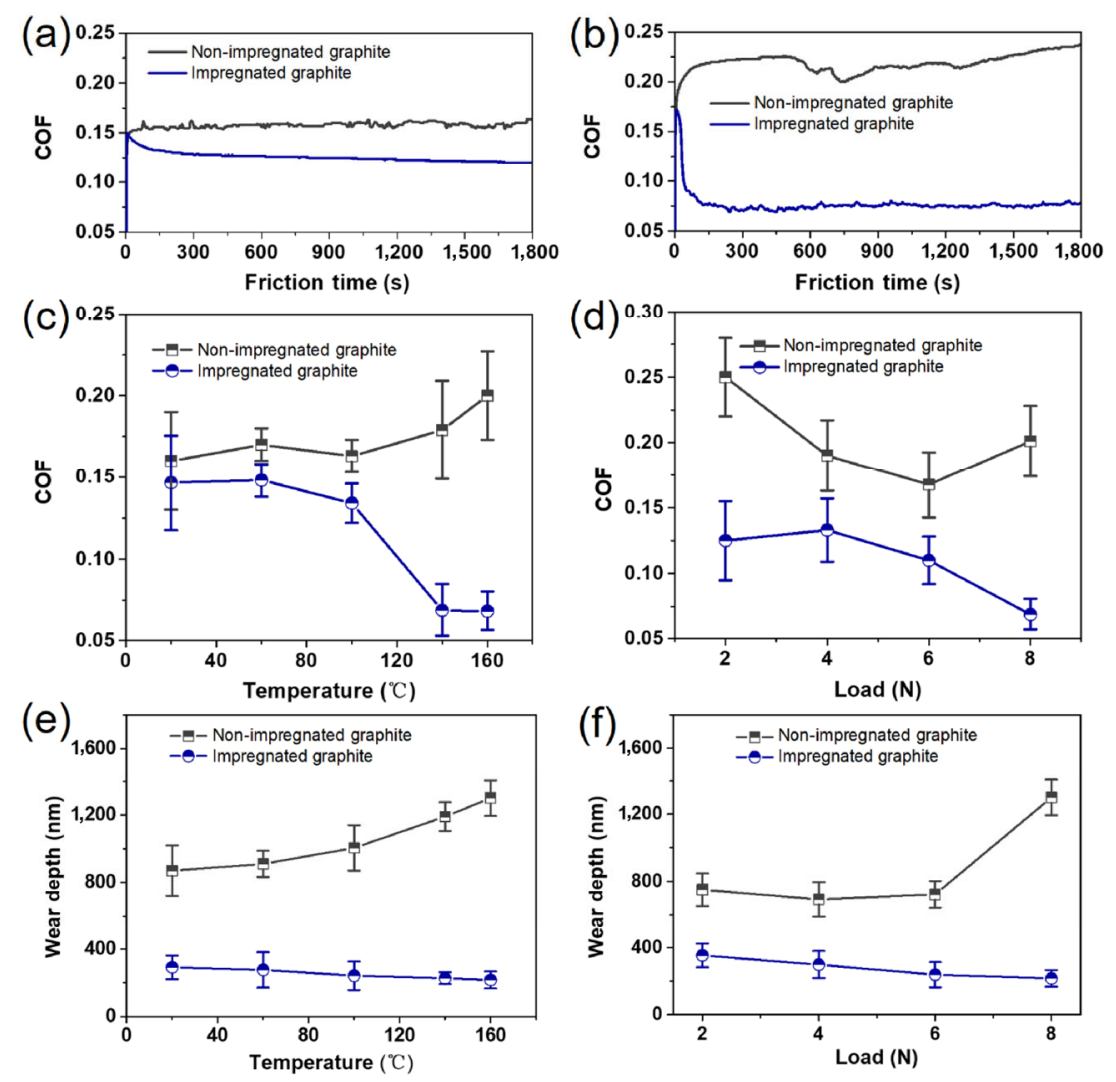

Fig. 3 COFs of impregnated graphite and non-impregnated graphite at the temperatures of $20{ }^{\circ} \mathrm{C}(\mathrm{a})$ and $160{ }^{\circ} \mathrm{C}$ (b), and $\mathrm{COFs}$ as a function of temperature under a load of $8 \mathrm{~N}$ (c). COFs as a function of load at $160^{\circ} \mathrm{C}(\mathrm{d})$. Anti-wear properties of impregnated graphite and non-impregnated graphite at different temperatures under a load of $8 \mathrm{~N}(\mathrm{e})$. Comparison of the anti-wear properties at $160{ }^{\circ} \mathrm{C}$ under different loads (f). 
impregnated graphite increases, which indicates that the pure graphite displays poor friction properties at high temperatures [7, 28, 29]. In addition, the impregnated graphite exhibits better anti-friction properties than the non-impregnated graphite under different loads as shown in Fig. 3(d). The value of the COF can be reduced by $50 \%$ and $68 \%$, respectively, under the loads of $2 \mathrm{~N}$ and $8 \mathrm{~N}$ compared with that of non-impregnated graphite.

\subsection{Wear behaviors}

The wear track depths of the impregnated and nonimpregnated graphite were subsequently measured and are shown in Figs. 3(e) and 3(f), respectively. The anti-wear properties of the non-impregnated graphite are less stable than those of the impregnated graphite. The wear depth of non-impregnated graphite increases with an increase in temperature probably because water vapor or other condensable vapors in the environment are desorbed from the graphite surfaces, resulting in high friction and high wear behaviors. This implies that the impregnation of resin enhances the anti-wear properties of graphite at different temperatures. In addition, the anti-wear properties of non-impregnated graphite are very poor under a high load of $8 \mathrm{~N}$. The wear depths of the impregnated graphite can be reduced by $52 \%$ under $2 \mathrm{~N}$ and $77 \%$ under $8 \mathrm{~N}$ than those of the non-impregnated graphite. Furthermore, according to the optical micrographs and cross sections of wear tracks displayed in Fig. 4, the rubbing surfaces of the impregnated graphite are very narrow and smooth. For comparison, those of the non-impregnated graphite display slender tracks and wide furrows at a high friction temperature $\left(160^{\circ} \mathrm{C}\right)$ or a low friction temperature $\left(20^{\circ} \mathrm{C}\right)$. This confirms that the impregnated graphite shows much better anti-wear properties than the non-impregnated graphite.

\subsection{Friction mechanism}

Water vapor or other condensable vapors in the environment can adsorb on the graphite surface, improving the formation of a transfer film and reducing the friction and wear effectively. However, the properties of the non-impregnated graphite are poor at high friction temperatures, as shown in Fig. 3, because the physically adsorbed water vapor from the graphite surfaces is prone to being desorbed at high temperatures, which could hinder the transformation of the carbon-based tribofilm. In addition, the nonimpregnated graphite suffers severe abrasive wear accompanied with material spalling, as shown in Fig. 5, because of its porous structure and poor mechanical properties [7, 9]. Wear debris and several wear cracks on the rubbing surfaces of the non-impregnated graphite, and rough wear ripples and ruptures are clearly observed at high temperatures $\left(160^{\circ} \mathrm{C}\right)$. For
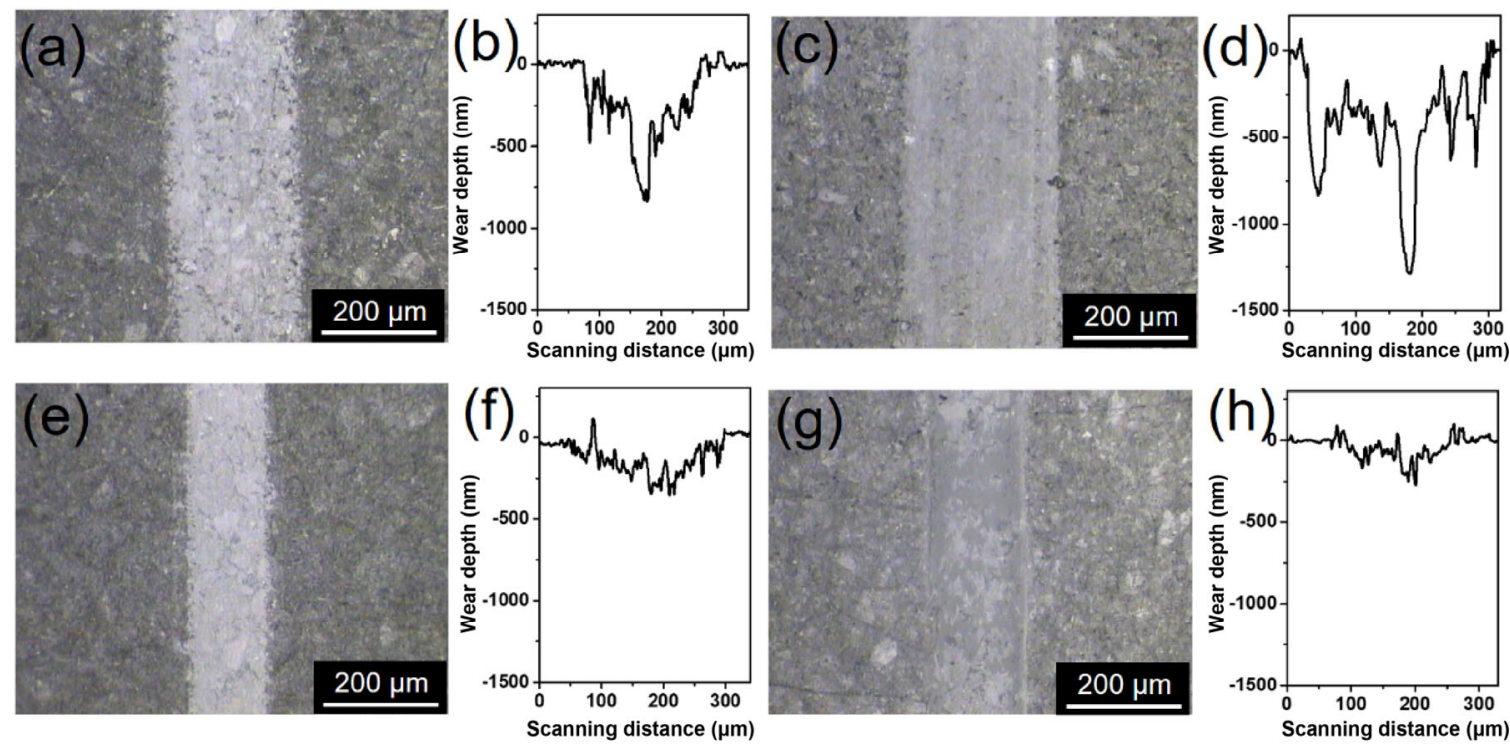

Fig. 4 Optical micrographs and cross sections of wear tracks under a load of $8 \mathrm{~N}$ : non-impregnated graphite at $20{ }^{\circ} \mathrm{C}(\mathrm{a}, \mathrm{b})$ and at $160{ }^{\circ} \mathrm{C}(\mathrm{c}, \mathrm{d})$; impregnated graphite at $20^{\circ} \mathrm{C}(\mathrm{e}, \mathrm{f})$ and $160{ }^{\circ} \mathrm{C}(\mathrm{g}, \mathrm{h})$. 

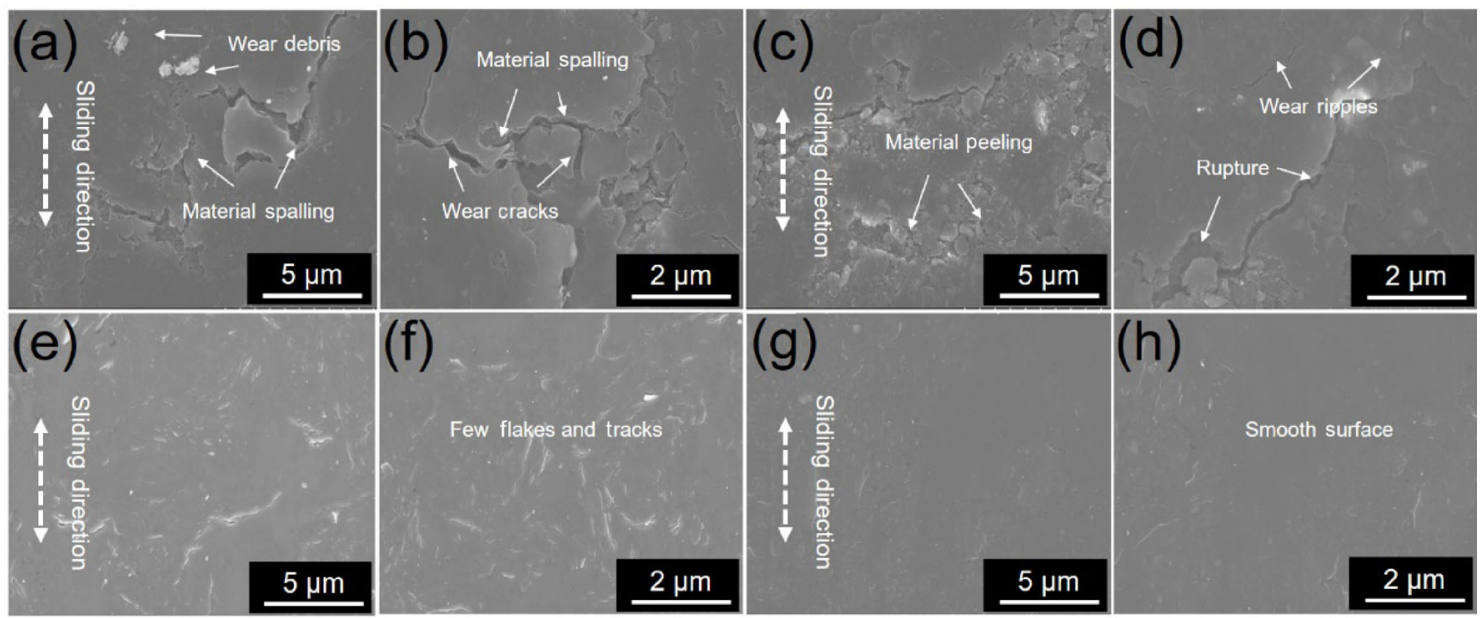

Fig. 5 SEM micrographs of wear tracks under a load of $8 \mathrm{~N}$ : non-impregnated graphite at $20{ }^{\circ} \mathrm{C}(\mathrm{a}, \mathrm{b})$ and at $160{ }^{\circ} \mathrm{C}(\mathrm{c}$, d); impregnated graphite at $20^{\circ} \mathrm{C}(\mathrm{e}, \mathrm{f})$ and at $160^{\circ} \mathrm{C}(\mathrm{g}, \mathrm{h})$.

the impregnated graphite, the rubbing surfaces exhibit fewer flakes and tracks than that of the non-impregnated graphite. In particular, at higher temperatures, only smoother ripples are seen on the rubbing surfaces, which indicates that the impregnated graphite has significant anti-wear properties. The above discussion agrees with the results of optical morphologies of wear tracks in Fig. 4. Therefore, the impregnating resin could effectively improve the tribological properties of graphite, which implies that the resin can encourage the formation of the carbon-based tribofilm at high temperatures.

According to the contact formula [13], the maximum and average pressures are calculated to be 510 and $350 \mathrm{MPa}$, respectively, for the friction couples under the load of $8 \mathrm{~N}$. Thus, there exists obvious material rupture and wear ripples owing to the high pressures shown in Fig. 5. In addition, the corresponding diameter of the Hertzian contact is about $170 \mu \mathrm{m}$. As shown in Fig. 6, the diameter of the wear scar increases from 200 to $260 \mu \mathrm{m}$, when the friction temperature changes from 20 to $160{ }^{\circ} \mathrm{C}$ for the friction couple of non-impregnated graphite sliding against a cemented carbide ball. There are more evident wear scratches on the wear scars of the ball at higher temperatures, and the main friction mechanism of the couple is abrasive wear. The wear scar diameter is strongly reduced for the ball sliding against impregnated graphite $(180 \mu \mathrm{m})$, which is close to the calculated Hertz diameter at $160{ }^{\circ} \mathrm{C}$. Therefore, the impregnated graphite has more significant anti- wear properties than the non-impregnated graphite at higher temperature. Energy disperse spectroscopy (EDS) elemental maps of the ball scars show low carbon content in the wear scars, which indicates that the carbon-based tribofilm from non-impregnated graphite cannot be effectively transferred onto the friction interfaces, especially at high temperatures.

For the cemented carbide ball sliding against the impregnated graphite, however, a significant amount of carbon is distributed at the center of wear scar as shown in Fig. 6(c); therefore, the impregnated resin can improve the formation of a transfer film. Furthermore, it can be clearly seen from Fig. 6(d) that the carbon-based tribofilm distributes more uniformly at $100{ }^{\circ} \mathrm{C}$ than that at $20^{\circ} \mathrm{C}$. When the friction temperature increases to $160{ }^{\circ} \mathrm{C}$, the tribofilm nearly spreads across the entire wear area, as shown in Fig. 6(e). There is a small quantity of elemental oxygen on the wear scars of the balls as shown in Figs. 6(k)6(o). The valence band energy regions of $\mathrm{W} 4 \mathrm{f}$ on the wear scars are shown in Fig. 7. The positions of fitted peaks in Figs. 7(a)-7(b) show obvious amounts of $\mathrm{WO}_{3}$ (at 34.5 and $36.7 \mathrm{eV}$ ) because of the oxidation of WC (at 31.8 and $33.9 \mathrm{eV}$ ) during friction [10, 30]. Oxidized tribofilms can form a low shear-resistance film and improve the tribological properties of tribopairs. However, the distribution of oxygen is not evenly distributed on the cemented carbide ball sliding against the non-impregnated graphite, as shown in Fig. 6(1), which suggests that the related oxidized tribofilm is not uniform. In contrast, although the 


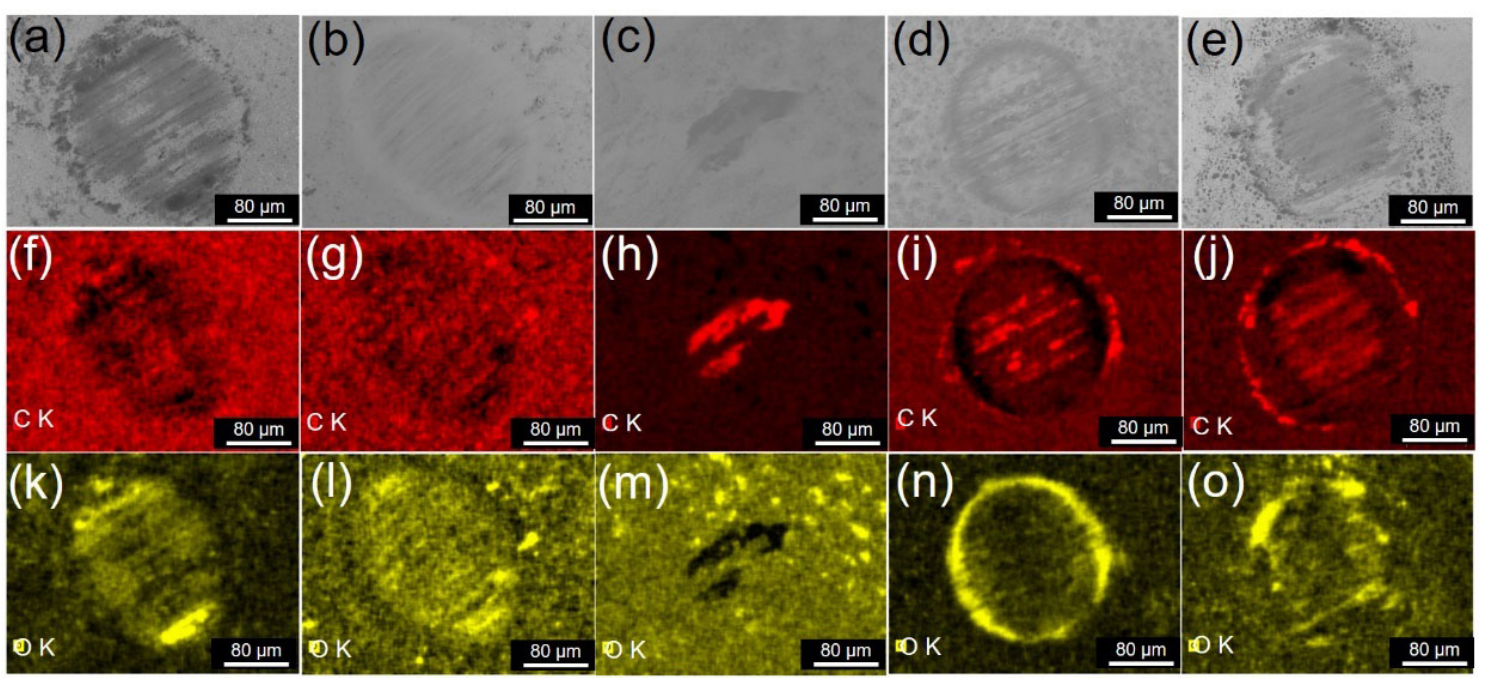

Fig. 6 SEM micrographs and EDS maps of the wear scars of cemented carbide balls under a load of $8 \mathrm{~N}$ : the wear scars sliding against non-impregnated graphite at $20^{\circ} \mathrm{C}(\mathrm{a}, \mathrm{f}, \mathrm{k})$ and $160^{\circ} \mathrm{C}(\mathrm{b}, \mathrm{g}, \mathrm{l})$; the scars sliding against impregnated graphite at $20^{\circ} \mathrm{C}(\mathrm{c}, \mathrm{h}, \mathrm{m}), 100{ }^{\circ} \mathrm{C}$ $(\mathrm{d}, \mathrm{i}, \mathrm{n})$, and $160^{\circ} \mathrm{C}(\mathrm{e}, \mathrm{j}, \mathrm{o})$.

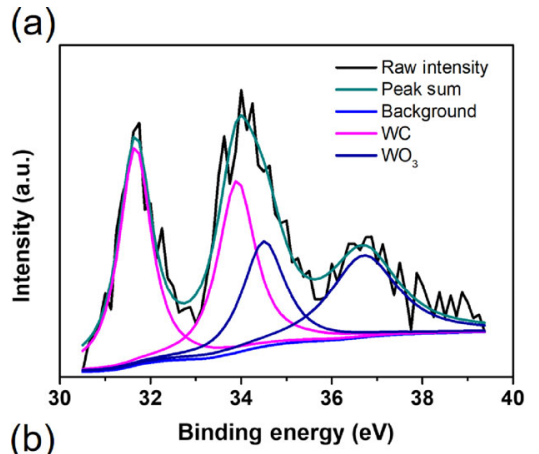

(b)

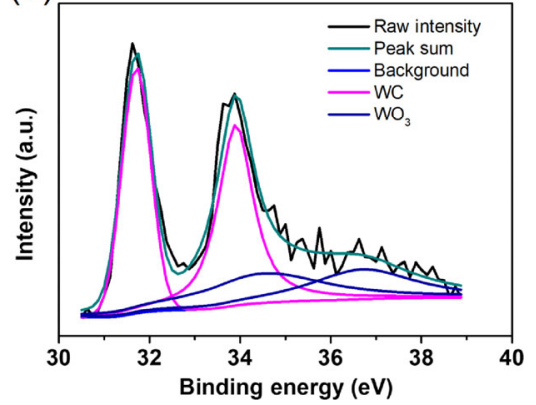

Fig. 7 The XPS of the valence band energy region of $\mathrm{W} 4 \mathrm{f}$ on the wear scars of cemented carbide balls sliding against non-impregnated graphite (a) and impregnated graphite (b) at $160{ }^{\circ} \mathrm{C}$ under a load of $8 \mathrm{~N}$.

oxidized tribofilm on the cemented carbide ball sliding against the impregnated graphite does not fully cover the friction interface shown in Fig. 6(o), a uniform and stable carbon-based tribofilm is transferred onto the interface in Fig. 6(j). Therefore, the tribopair of the impregnated graphite/cemented carbide displays significant tribological properties.
The Raman spectra of the initial graphite and corresponding wear areas are shown in Fig. 8. The spectrum of the non-impregnated graphite has three typical characteristic peaks: the D peak at $1,350 \mathrm{~cm}^{-1}$, $\mathrm{G}$ peak at $1,580 \mathrm{~cm}^{-1}$, and $2 \mathrm{D}$ peak at $2,710 \mathrm{~cm}^{-1}$. The $\mathrm{G}$ and 2D peaks correspond to the bond stretching of the in-plane vibration of $\mathrm{sp}^{2}$ atoms and reflect the order of the structure of graphite [31-33]. The D peak is attributed to disorder in graphite, and the intensity ratio of $I_{\mathrm{D}} / I_{\mathrm{G}}$ is a measure of disorder degree in graphite [34-36]. As shown in Fig. 8(a), the structure of the non-impregnated graphite exhibits a high degree value of order because the intensity of the $G$ peak is higher than that of $\mathrm{D}$ peak. However, the $\mathrm{D}$ peak measured on the wear track of the non-impregnated graphite increases obviously after friction, indicating that the structure of the non-impregnated graphite becomes disordered owing to friction. In addition, the carbon-based tribofilm from the non-impregnated graphite is formed on the friction interfaces according to the Raman spectrum, whereas the intensity ratio of $I_{\mathrm{D}} / I_{\mathrm{G}}$ in the wear scar is very large and much higher than that of the wear track.

After friction, another Raman peak G+D (at $2,945 \mathrm{~cm}^{-1}$ ) is generated on the wear track and wear scar, confirming that the structure of graphite has become more disordered [37]. Hence, although the non-impregnated graphite is able to form a transfer film, the corresponding carbon-based tribofilm exhibits 

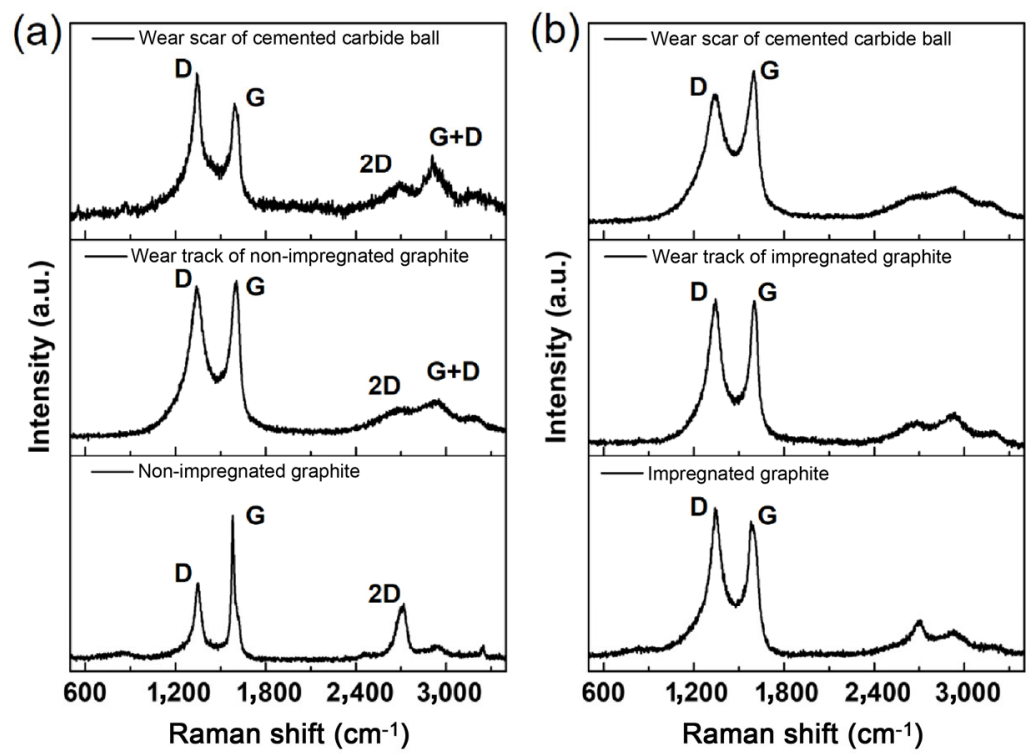

Fig. 8 Raman spectra on the rubbing surfaces sliding against non-impregnated graphite (a) and impregnated graphite (b) at $160{ }^{\circ} \mathrm{C}$ under a load of $8 \mathrm{~N}$.

many defects and disorder, thereby resulting in worse tribological properties. As shown in Fig. 8(b), the initial impregnated graphite has a slightly higher intensity of the D peak than the non-impregnated graphite, which is probably because some defects are generated in the graphite during the resin impregnation process [1]. However, the structure of the impregnated graphite becomes disordered because the intensity of the $\mathrm{D}$ peak decreases during friction. Furthermore, the crystallite size of graphite (La) can be calculated based on the Truinstra and Koening formulae [19]. The La value of the non-impregnated graphite is $7.6 \mathrm{~nm}$, and it decreases to $3.1 \mathrm{~nm}$ after friction in the wear track. For comparison, the structure of the impregnated graphite becomes ordered because the value of La increases from 4.2 (impregnated graphite) to $5.3 \mathrm{~nm}$ (wear track) by friction. Therefore, the impregnated graphite can form a stable transfer film induced by friction temperature on the rubbing surfaces, whose structure is ordered [34]. As a result, outstanding tribological properties can be achieved as the ordered carbon-based tribofilm can easily slide between graphite layers.

\section{Conclusions}

The tribological properties of impregnated graphite were investigated at different friction temperatures and compared with those of non-impregnated graphite; furthermore, the critical effect of the carbon-based tribofilm induced by friction temperature was determined. The main conclusions are as follows:

(1) The anti-friction properties of impregnated graphite are much better than those of non-impregnated graphite. The $\mathrm{COF}$ value of impregnated graphite decreases with an increase in the friction temperature, i.e., it is reduced by $30 \%$ at $20{ }^{\circ} \mathrm{C}$ and $68 \%$ at $160{ }^{\circ} \mathrm{C}$, compared with that of non-impregnated graphite. Therefore, the friction temperature directly influences the tribological properties of graphite, which improves the properties of impregnated graphite significantly.

(2) The wear depth of the impregnated graphite is reduced by $40 \%$ when the friction temperature changes from 20 to $160{ }^{\circ} \mathrm{C}$, and only a few flakes and smooth ripples can be observed on the wear tracks, whereas the wear tracks of the non-impregnated graphite show obvious wear cracks and wear debris, and rough wear ripples and rupture are clearly observed on the rubbing surfaces.

(3) The carbon-based tribofilm induced by the friction temperature has a critical effect on the tribological properties of graphite. The tribofilm adsorbs on the friction interfaces more uniformly and stably with an increase in temperature. Furthermore, its structure becomes more ordered during friction, meaning that graphite can easily slide between its layers. In addition, 
the carbon-based tribofilm can not only improve the tribological properties of graphite, but also promote the antioxidation performance of the friction couple.

The findings of this study provide insight into the evolution mechanism of carbon-based tribofilms, providing an important basis for improving the tribological properties of graphite-based friction materials for numerous applications.

\section{Acknowledgements}

This work is supported by the National Key R\&D Program of China (No. 2018YFB2000801), the National Natural Science Foundation of China (No. 51905027), the Tribology Science Fund of State Key Laboratory of Tribology (No. SKLTKF18A02), and the Fundamental Research Funds for the Central Universities (No. BUCTRC201908).

Open Access: This article is licensed under a Creative Commons Attribution 4.0 International License, which permits use, sharing, adaptation, distribution and reproduction in any medium or format, as long as you give appropriate credit to the original author(s) and the source, provide a link to the Creative Commons licence, and indicate if changes were made.

The images or other third party material in this article are included in the article's Creative Commons licence, unless indicated otherwise in a credit line to the material. If material is not included in the article's Creative Commons licence and your intended use is not permitted by statutory regulation or exceeds the permitted use, you will need to obtain permission directly from the copyright holder.

To view a copy of this licence, visit http://creativecommons.org/licenses/by/4.0/.

\section{References}

[1] Zhang G L, Liu Y, Guo F, Liu X F, Wang Y M. Friction characteristics of impregnated and non-impregnated graphite against cemented carbide under water lubrication. J Mater Sci Technol 33(10): 1203-1209 (2017)

[2] Sakka M M, Antar Z, Elleuch K, Feller J F. Tribological response of an epoxy matrix filled with graphite and/or carbon nanotubes. Friction 5(2): 171-182 (2017)
[3] Rietsch J C, Brender P, Dentzer J, Gadiou R, Vidal L, VixGuterl C. Evidence of water chemisorption during graphite friction under moist conditions. Carbon 55: 90-97 (2013)

[4] Gulevskii V A, Antipov V I, Kolmakov A G, Vinogradov L V, Lazarev E M, Mukhina Y E, Gordeev A S. Designing of copper-based alloys for the impregnation of carbon-graphite materials. Russ Metall 2012(3): 258-261 (2012)

[5] Savchenko D, Serdan A, Morozov V, Van Tendeloo G, Ionov S G. Improvement of the oxidation stability and the mechanical properties of flexible graphite foil by boron oxide impregnation. New Carbon Mater 27(1): 12-18 (2012)

[6] Hirani H, Goilkar S S. Formation of transfer layer and its effect on friction and wear of carbon-graphite face seal under dry, water and steam environments. Wear 266(11-12): 1141-1154 (2009)

[7] Zhu Z G, Bai S, Wu J F, Xu L, Li T, Ren Y, Liu C. Friction and wear behavior of resin/graphite composite under dry sliding. J Mater Sci Technol 31(3): 325-330 (2015)

[8] Wang Y A, Li J X, Yan Y, Qiao L J. Effect of surface film on sliding friction and wear of copper-impregnated metallized carbon against a $\mathrm{Cu}-\mathrm{Cr}-\mathrm{Zr}$ alloy. Appl Surf Sci 258(7): 2362-2367 (2012)

[9] Qian J, Yuan X Y, Zhang G Y, Dong G N, Zhao W G. Dry friction and wear characteristics of impregnated graphite in a corrosive environment. Chin J Mech Eng 27(5): 965-971 (2014)

[10] Zhang G L, Liu Y, Wang Y C, Guo F, Liu X F, Wang Y M. Wear behavior of WC-Ni sliding against graphite under water lubrication. J Mater Sci Technol 33(11): 1346-1352 (2017)

[11] Bryant P J, Gutshall P L, Taylor L H. A study of mechanisms of graphite friction and wear. Wear 7(1): 118-126 (1964)

[12] Dienwiebel M, Verhoeven G S, Pradeep N, Frenken J W M, Heimberg J A, Zandbergen H W. Superlubricity of graphite. Phys Rev Lett 92(12): 126101 (2004)

[13] Zhao J, He Y Y, Wang Y F, Wang W, Yan L, Luo J B. An investigation on the tribological properties of multilayer graphene and $\mathrm{MoS}_{2}$ nanosheets as additives used in hydraulic applications. Tribol Int 97: 14-20 (2016)

[14] Bowden F P, Young J E. Friction of diamond, graphite, and carbon and the influence of surface films. Pro R Soc A Math Phys Eng Sci 208(1095): 444-455 (1951)

[15] Berman D, Erdemir A, Sumant A V. Graphene: a new emerging lubricant. Mater Today 17(1): 31-42 (2014)

[16] Wang Q H, Zhang X R, Pei X Q. Study on the synergistic effect of carbon fiber and graphite and nanoparticle on the friction and wear behavior of polyimide composites. Mater Des 31(8): 3761-3768 (2010)

[17] Batchelor A W, Lam L N, Chandrasekaran M. Lubrication 
of stellite at ambient and elevated temperatures by transfer films from a graphite slider. Wear 198(1-2): 208-215 (1996)

[18] Williams J A, Morris J H, Ball A. The effect of transfer layers on the surface contact and wear of carbon-graphite materials. Tribol Int 30(9): 663-676 (1997)

[19] Lafon-Placette S, Delbé K, Denape J, Ferrato, M. Tribological characterization of silicon carbide and carbon materials. $J$ Eur Ceram Soc 35(4): 1147-1159 (2015)

[20] Chang L, Zhang Z, Ye L, Friedrich K. Tribological properties of epoxy nanocomposites: III. Characteristics of transfer films. Wear 262(5-6): 699-706 (2007)

[21] Ye J X, Burris D, Xie T. A review of transfer films and their role in ultra-low-wear sliding of polymers. Lubricants 4(1): 4 (2016)

[22] Myshkin N, Kovalev A, Spaltman D, Woydt M. Contact mechanics and tribology of polymer composites. $J$ Appl Polym Sci 131(3): 39870 (2014)

[23] Che Q L, Zhang G, Zhang L G, Qi H M, Li G T, Zhang C, Guo F. Switching brake materials to extremely wear-resistant self-lubrication materials via tuning interface nanostructures. ACS Appl Mater Interfaces 10(22): 19173-19181 (2018)

[24] Li C, Li S F, Yan S L. Facile and green preparation of biobased graphene oxide/furan resin nanocomposites with enhanced thermal and mechanical properties. RSC $A d v$ 6(67): 62572-62578 (2016)

[25] Gandini A, Coelho D, Gomes M, Reis B, Silvestre A. Materials from renewable resources based on furan monomers and furan chemistry: work in progress. J Mater Chem 19(45): 8656-8664 (2009)

[26] Xu Z W, Huang Y D, Zhang C H, Liu L, Zhang Y H, Wang L. Effect of $\gamma$-ray irradiation grafting on the carbon fibers and interfacial adhesion of epoxy composites. Compos Sci Technol 67(15-16): 3261-3270 (2007)

[27] Zhao J, Li Y R, He Y Y, Luo J B. In situ green synthesis of the new sandwichlike nanostructure of $\mathrm{Mn}_{3} \mathrm{O}_{4} /$ Graphene as lubricant additives. ACS Appl Mater Interfaces 11(40):

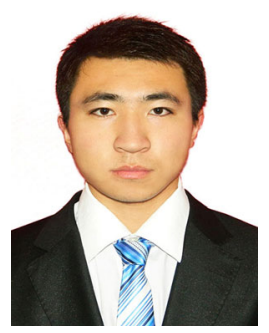

Jun ZHAO. He received his Ph.D. degree in mechanical engineering from Tsinghua University, China. $\mathrm{He}$ is an associate professor in College of Mechanical and Electrical
36931-36938 (2019)

[28] Yen B K, Ishihara T. An investigation of friction and wear mechanisms of carbon-carbon composites in nitrogen and air at elevated temperatures. Carbon 34(4): 489-498 (1996)

[29] Samyn P, Schoukens G. The lubricity of graphite flake inclusions in sintered polyimides affected by chemical reactions at high temperatures. Carbon 46(7): 1072-1084 (2008)

[30] Katrib A, Hemming F, Wehrer P, Hilaire L, Maire G. The multi-surface structure and catalytic properties of partially reduced $\mathrm{WO}_{3}, \mathrm{WO}_{2}$ and $\mathrm{WC}+\mathrm{O}_{2}$ or $\mathrm{W}+\mathrm{O}_{2}$ as characterized by XPS. J Electron Spectrosc Relat Phenom 76: 195-200 (1995)

[31] Ferrari A C. Raman spectroscopy of graphene and graphite: Disorder, electrona-phonon coupling, doping and nonadiabatic effects. Solid State Commun 143(1-2): 47-57 (2007)

[32] Sadezky A, Muckenhuber H, Grothe H, Niessner R, Pöschl U. Raman microspectroscopy of soot and related carbonaceous materials: Spectral analysis and structural information. Carbon 43(8): 1731-1742 (2005)

[33] Graf D, Molitor F, Ensslin K, Stampfer C, Jungen A, Hierold C, Wirtz L. Spatially resolved Raman spectroscopy of single- and few-layer graphene. Nano Lett 7(2): 238-242 (2007)

[34] Zhao J, Mao J Y, Li Y R, He Y Y, Luo J B. Friction-induced nano-structural evolution of graphene as a lubrication additive. Appl Surf Sci 434: 21-27 (2018)

[35] Zhao J, Li Y R, Mao J Y, He Y Y, Luo J B. Synthesis of thermally reduced graphite oxide in sulfuric acid and its application as an efficient lubrication additive. Tribol Int 116: 303-309 (2017)

[36] Tuinstra F, Koenig J L. Raman spectrum of graphite. $J$ Chem Phys 53(3): 1126-1130 (1970)

[37] Berman D, Erdemir A, Sumant A V. Few layer graphene to reduce wear and friction on sliding steel surfaces. Carbon 54: 454-459 (2013)

Engineering, Beijing University of Chemical Technology, China. His research interests cover the synthesis of advanced lubricating nanomaterials and applications of antifriction and antiwear materials. 


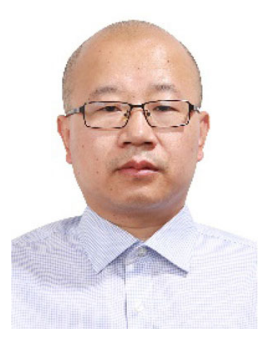

Shuangxi LI. He received his M.S. and Ph.D. degrees in College of Mechanical and Electrical Engineering from Beijing University

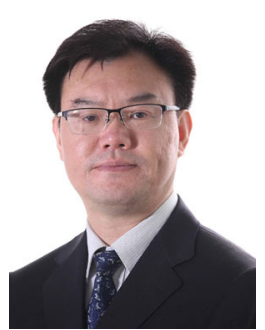

Yongyong HE. He received his M.S. and Ph.D. degrees in mechanical engineering from Southeast University, China, in 1994 and 1997, respectively. He joined Tsinghua of Chemical Technology (BUCT), Beijing, China, in 2000 and 2003, respectively. He current is an associate professor in BUCT. His research areas cover the fluid machinery and sealing technology.

University from 1999. Now, he is a professor in the State Key Laboratory of Tribology. His research areas cover surface/interface modification, chemical mechanical polishing, and ultra-smooth surface polishing. 